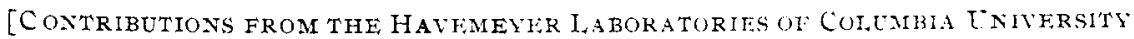
NO. IAI].

\title{
DETERMINATION OF MOLECULAR WEIGHTS BY DISTRIBUTION EXPERIMENTS'.
}

By J. L.TVINGSTON R. MOR(IAN ANI II. K. BHASON

Received June II, 1907 .

According to Nernst ${ }^{2}$ and Aulich ${ }^{3}$ and others ${ }^{4}$ it is possible to find the relation existing between the molecular weights of a substance in two immiscible solvents by distributing it between them. The simplest derivation of this law is the following:

Assume the formula of a substance to be $A$ in one solvent, and $A_{n}$ in the other immiscible one, where $n$ is equal to I, or greater. The chemical reaction in the two-layer, heterogeneous system, then, will be

$$
n A=A_{n}
$$

and the application of the law of mass action will lead to the relation $C_{A n}$ $C_{A}^{n}==$ constant, where $C_{A n}$ and $C_{A}$ are the concentrations in moles, per unit of volume, of the substances $A_{n}$ and $A$ in the two layers.

This constant is of course independent of the single values of $\mathbf{C}_{\mathbf{A} n}$ and $\mathrm{C}_{\mathrm{A}}$, and dependent only upon the temperature.

If $n \cdots \quad$, the substance being a gas which is distributed between a liquid and a space above it, we have Henry's law, $i . c, \frac{C_{\text {asgas }}}{C_{\text {in }} \text { solution }}=$ constant. When $n=2$, as is the case when the solvents are water and

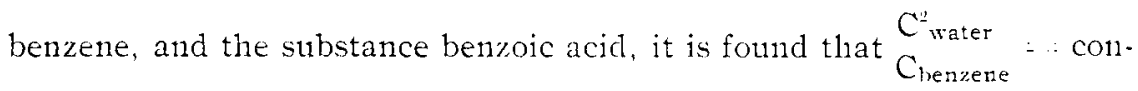
stant, at any one temperature and indepencient of the total amount of benzoic acid present in the system.

In place of concentration, $i . e_{\text {, }}$, moles per liter, we can employ grams per unit volume. Thus, since $\mathrm{C}_{1}=\frac{u_{1}^{\prime}}{\mathrm{M}_{2}} \mathrm{C}_{2}=\frac{\pi_{2}}{\mathrm{M}_{2}}$, and $\mathrm{M}_{1}=n \mathrm{M}_{2}$ we find that - constant $=\mathrm{C}_{1} / \mathrm{C}_{2}{ }^{\prime \prime}$ - can also be written in the form $\left(\left(\mathrm{M}_{1} / \mathrm{M}_{2}{ }^{n}\right)\right.$ constant $)=z w_{1} / w_{2}^{\prime} n$, where $w_{1}$ and $w_{2}$ are the grams in the two layers per unit of volume. In other words, so long as at all dilutions $\mathrm{M}_{1} / \mathrm{M}_{2}{ }^{n}$ is a constant, we can use $w_{1} / w_{2}{ }^{n}$ in place of $\mathrm{C}_{1} / \mathrm{C}_{2}{ }^{n}$. And, conversely, if $w_{1} / w_{2}$ is a constant for all dilutions, $M_{1}$ must be equal to $M_{2}$.

1 Abstract from the Iissertation (Columbia Igo7) of H. K. Benson.

:Z. physik. chem., 8, IIO, (189I).

"Ibid, 8, I05. (189I).

4 See Hantzsh and Sebalt, ibid, 30, 268, (I896); Hantzsch and Vagt, ibid, 38, 705. (1901); Roloff, Ibid, 13, 341. (1894); Jakowkin, Ibid, 20, 19, (1896); Hendrixson, Z. anorg. Chem., 13, 73, (I897); Riecke, Z. physik. Chem., 7, IOS, (IS9I); H. Fischer, Dissertation, Breslau, (I905); Herz and Lewy, Z. electrochen., 11, 818, (1905) and others. 
The substances studied in this investigation were those which absorb heat on dissolving, and show variation in the molecular weight with the concentration, according to the freezing point method; together with those which were necessary to interpret these. The results of the distribution experiments, expressed in grams per cc., are as follows :

I.

ACetic Acid Between Water and Ether.

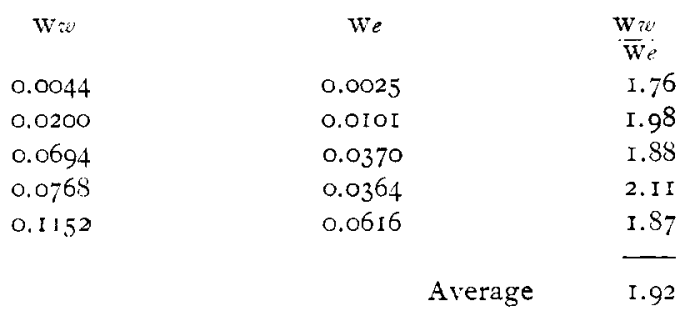

II. ACetic Acid Between Mol,ten $\mathrm{CaCl}_{2}, 6 \mathrm{H}_{2} \mathrm{O}$ axd Éther.

$\begin{array}{ccc}\text { Ws } & \text { We } & \frac{W_{s}}{W_{e}} \\ 0.0124 & 0.0175 & 0.709 \\ 0.0216 & 0.0285 & 0.757 \\ 0.0249 & 0.0358 & 0.696 \\ 0.0518 & 0.0767 & 0.675 \\ 0.0933 & 0.1229 & 0.759 \\ 0.1298 & 0.1940 & 0.669 \\ & & \\ & & \text { Average } \\ & & 0.711\end{array}$

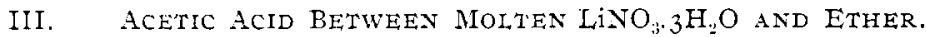

\begin{tabular}{|c|c|}
\hline $\mathbf{w}_{s}$ & $\mathrm{w} e$ \\
\hline 0.0092 & 0.0072 \\
\hline 0.0216 & 0.0194 \\
\hline 0.0261 & 0.0249 \\
\hline 0.0533 & 0.0508 \\
\hline 0.0869 & 0.0869 \\
\hline
\end{tabular}

IV. Ethyl Alcohol Between Water and Ether.

$\begin{array}{ccc}\mathrm{W} w & \text { We } & \frac{\mathrm{w} w}{\mathrm{~W} e} \\ 0.0116 & 0.0164 & 0.707 \\ 0.0289 & 0.0496 & 0.583 \\ 0.0543 & 0.0833 & 0.652 \\ 0.0660 & 0.1157 & 0.570 \\ 0.0689 & 0.1127 & 0.61 \mathrm{I} \\ 0.102 & 0.1996 & 0.538\end{array}$

Average $\quad 0.610$ 
V. ETHYL ALCOHOL BHTWEEN AIOLTEN $\mathrm{CaCl}_{2} .6 \mathrm{H}_{2} \mathrm{O}$ AND ETHER.

\begin{tabular}{|c|c|c|}
\hline $\mathrm{w} s$ & $\mathrm{w}_{r}$ & $W_{e}$ \\
\hline 0.0039 & 0.00387 & I.Gi \\
\hline 0.025 & 0.0247 & I.CI \\
\hline 0.025 & 0.0210 & 1.19 \\
\hline 0.0388 & 0.0332 & 1.14 \\
\hline $0.046_{3}$ & 0.0369 & I. 26 \\
\hline 0.098 & 0.0764 & 1.27 \\
\hline
\end{tabular}

VI. Ethyl Alcohol Betweer Molten CaCl $2.6 \mathrm{H}_{2} \mathrm{O}$ AND BeNzeNe. W: Wo Wis

$\begin{array}{lll}0.288 & 0.0382 & 76 \\ 0.4566 & 0.0606 & 7.54 \\ & 135\end{array}$

VII. ETHYL Alcohol BeTweex WATER AND BenZENE.

$\begin{array}{lll}W & w b & w w \\ 0.040 & & w b \\ 0.0693 & 0.0385 & 1.04 \\ 0.160 & 0.0683 & 1.02 \\ 0.262 & 0.1316 & 1.22 \\ & 0.1936 & 1.36\end{array}$

Equal volumes of the two solvents were used throughout, in each case the system being agitated at $25^{\circ}$ until equilibrium was established. The acetic acid was titrated with a standard base, using phenolphthalein as indicator. The content of alcohol in the two layers was found by the Method of Thorpe and Holmes'. $25 \mathrm{cc}$. of the laver were removed and placed in a separating funnel, diluted to $100 \mathrm{cc}$. With water, saturated with sodium chloride and mixed with $40 \mathrm{cc}$. of petrolenm ether. After shaking for five minutes the layers were allowed to separate and the lower one withdrawn for distillation. The layer of petroleum ether was washed several times with saturated salt solution and the washings addec to the main portion. The latter was next distilled through a Hopkins head and condenser into a $50 \mathrm{cc}$. flask, protected against evaporation by an adapter. The flask, after distillation had continued until one-fourth of the original solution had distilled over, was filled to the mark with distilled water. To determine the alcohol in grams in this distillate, the specific gravity was determined by aid of a Sprengel-Ostwald pycnometer and from that, by means of the conversion table of Morle ${ }^{2}$; the percentage of alcohol by weight determined. This weight was the amount of alcohol present in the original $25 \mathrm{cc}$.

\section{Discussion of Results}

Before using ether as the second solvent it was necessary to find the molecular weights of alcohol and acetic acid, when dissolved in it. As

${ }^{1} \mathrm{~J}$. Chem. Soc., 83, 314, (1903).

"This Journal, 26, II 85. (1904). 
these cannot be found by aid of the freezing point, and since solute, as well as solvent, distils when heated the boiling point method is not applicable, there is no direct method. The method used was as follows: The molecular weights of ethyl alcohol and acetic acid in water have been determined up to high concentrations'; and increase but slightly with increased concentration. Solutions of acetic acid and ethyl alcohol in water were shaken with equal volumes of ether, and gave (see tables I and IV) practically constant results, within the experimental error. Tables II, III, and $\mathrm{V}$ also show constancy in the ratio for acetic acid between ether and $\mathrm{CaCl}_{2} \cdot 6 \mathrm{H}_{2} \mathrm{O}$ and $\mathrm{LiNO}_{3} \cdot{ }_{3} \mathrm{H}_{2} \mathrm{O}$, and alcohol between ether and $\mathrm{CaCl}_{2} \cdot 6 \mathrm{H}_{2} \mathrm{O}$. This proves, then, that acetic acid and alcohol have practically the same molecular weights in ether as they have in water (which is nearly independent of concentration, as shown by the freezing point method); and that this molecular weight is really the same as that in molten $\mathrm{CaCl}_{2} \cdot 6 \mathrm{H}_{2} \mathrm{O}$, notwithstanding that the freezing point leads, according to Morgan and Benson, to absurd figures at high concentrations. Further, according to the coefficient of distribution the molecular weight of alcohol in benzene, (table VII) even ignoring the experimental error, does not vary as greatly with the concentration as it does according to the freezing points of Beckmann", who finds the value $\mathrm{M}=3 \mathrm{I} 8$ for a solution containing 32.45 grams of alcohol to $\mathrm{IOO}$ of benzene.

Throughout, of course, all consideration of ionization has been omitted, for in all cases considered it is negligible, as compared with the experimental error; and simplicity rather than great exactness was thought impertant.

\section{Summary.}

I. The molecular weights of ethyl alcohol and acetic acid in ether are the same as in water, i. e., $\mathrm{C}_{w} \mathrm{C}_{e}^{-}$, for both acetic acid and alcohol is constant and independent of dilution.

II. The molecular weights of alcohol and acetic acid in molten $\mathrm{CaCl}_{2} \cdot 6 \mathrm{H}_{2} \mathrm{O}$ and in $\mathrm{LiNO}_{3} \cdot 3 \mathrm{H}_{2} \mathrm{O}$. derived from the coefficient of distribution, are the same as in water, although freezing point measurements, according to Morgan and Benson, using the ordinary formula, lead to absurd values in concentrated solutions.

III. The molecular weight of alcohol in benzene, derived from the coefficient of distribution, apparently does not vary with the concentration to such a great extent as it does when derived from the freezing point method.

LABORATORY OF PHYSICAL CHEMISTRY, JUNE, 1907.

1 Jones and Murray, Am. Ch. J., 30, 205, (1903).

ZZ. physik. Chem., 2, 728, (1888). 